\title{
Phase II Study of the Efficacy and Safety of High-dose Pemetrexed in Combination with Cisplatin Versus Temozolomide for the Treatment of Non-small Cell Lung Cancer with Brain Metastases
}

\author{
QIAOWEI HE ${ }^{1 *}$, XIZHUANG BI ${ }^{2 *}, \mathrm{CHAO} \mathrm{REN}^{2}, \mathrm{YONG}_{\mathrm{WANG}}{ }^{3}, \mathrm{PENG} \mathrm{ZOU}^{1}, \mathrm{HONGTAO} \mathrm{ZHANG}^{1}$, \\ NAN CHI ${ }^{1}, \mathrm{CHUNMING}^{\mathrm{XIU}}{ }^{1}$, YUNBO WANG $^{1}$ and RONGJIE TAO ${ }^{3}$ \\ Departments of ${ }^{1}$ Neurosurgery, and ${ }^{2}$ Neurology, \\ the Affiliated Yantai Yuhuangding Hospital of Qingdao University, Yantai, P.R. China; \\ ${ }^{3}$ Department of Neurosurgery, Shandong Cancer Hospital, Jinan, P.R. China
}

\begin{abstract}
The aim of this study was to explore the efficacy and safety of high-dose pemetrexed with cisplatin versus combination with temozolomide in patients with brain metastases (BM) of lung adenocarcinoma. After standard whole-brain radiotherapy (WBRT, 30 Gy/l0 fractions), patients with BM of non-small cell lung cancer (NSCLC) were given high-dose pemetrexed $\left(900 \mathrm{mg} / \mathrm{m}^{2}\right)$ on day 1 of each cycle (3 weeks), and cisplatin was administered on days 1-3 in the cisplatin-treated group. The temozolomidetreated group was treated as follows: $75 \mathrm{mg} / \mathrm{m}^{2}$ temozolomide orally with concurrent WBRT followed by 150 $\mathrm{mg} / \mathrm{m}^{2}$ temozolomide on days 1-5 with high-dose pemetrexed $\left(900 \mathrm{mg} / \mathrm{m}^{2}\right)$ on day 1 of each cycle (3 weeks). Six cycles later, high-dose pemetrexed $\left(900 \mathrm{mg} / \mathrm{m}^{2}\right)$ monotherapy or the best available supportive therapy was administered to both groups. An evaluation was carried out every 2-3 cycles. The primary end-points were objective response rate $(O R R)$, progression-free survival (PFS), and overall survival $(O S)$. Secondary end-points included safety and tolerability. Thirty-two patients in the pemetrexed plus cisplatin (PC) group and 28 patients in the pemetrexed plus temozolomide (PT) group were enrolled from November 2013 to October 2015. The ORR was $68.8 \%$ and $75 \%$, in the PC and PT
\end{abstract}

*These Authors contributed equally to this work

Correspondence to: Chao Ren, Department of Neurology, The Affiliated Yantai Yuhuangding Hospital of Qingdao University, Yantai, Shandong Province, 264000, P.R. China. Tel: +86 0535669199, Fax: +86 05356240341, e-mail: fairybxzh@163.com

Key Words: Lung adenocarcinoma, metastases, temozolomide, WBRT, high-dose pemetrexed. groups, respectively, and there was no statistically significant difference between the two groups $(p=0.711)$. The median PFS rates of the PC and PT groups were 13.6 months and 16.9 months, respectively, and the median OS rates of the PC and PT groups were 18.9 months and 19.3 months, respectively. There were no differences in PFS and OS between the two groups. There were no grade 4 or higher side-effects in either group, but grade 3 side-effects such as leucopenia (2/32, 6.3\%), nausea/vomiting (2/32, $6.3 \%)$, alopecia $(1 / 32,3.1 \%)$, rash $(3 / 32,9.4 \%)$ and renal insufficiency $(1 / 32,3.1 \%)$ were observed in the PC group, whereas the PT-group-only showed the following grade 3 side-effects: leucopenia $(1 / 28,3.6 \%)$ and nausea/vomiting (2/28, 7.1\%). The data showed that the PT group achieved the same efficacy in PFS and OS as the PC group but with fewer toxicities. Therefore, high-dose pemetrexed plus temozolomide may be a better regimen for treating NSCLC with BM due to its better safety.

Brain metastases (BM) are a source of significant morbidity and mortality and herald a poor prognosis in patients with metastatic lung cancer. Up to $30 \%$ of patients with lung cancer develop metastases during the evolution of their disease (1-3), and $10 \%$ of patients have metastases at the time of diagnosis (4). Surgery and stereotactic radiosurgery (SRS) have been extensively used to treat patients with brain metastases (4-7) with one to three brain metastases. Unfortunately, most cases of BM from non-small cell lung cancer (NSCLC) are unable to receive surgery or radiosurgery when they are diagnosed (8). The median survival time of patients with NSCLC with BM treated with whole-brain radiotherapy (WBRT) is 3-6 months, with a significant proportion of patients dying of intracranial progressive disease a few months after treatment $(9,10)$. 
The role of chemotherapy has been evaluated in few studies, with a modest, but clear efficacy that depends on the combination of drugs used (11). Pemetrexed, an inhibitor of thymidylate synthase, dihydrofolate reductase, and glycinamide ribonucleotide formyl transferase, has been shown to be effective against NSCLC with BM (12-14). As a first-line therapy for treating patients with stage IV NSCLC, pemetrexed plus cisplatin showed a $30.6 \%$ objective response rate (ORR), 4.8-month median progression free survival (PFS) and 10.3-month median overall survival (OS) (14). Dinglin et al. (13) investigated a 42-patient population and suggested that with concurrent WBRT, the objective cerebral response rate (RR) (complete and partial response) in the intent-to-treat population was $68.3 \%$ and that the extracerebral and ORR were $34.1 \%$ and $36.6 \%$, respectively. The PFS of patients with BM was 10.6 months, and the median OS was 12.6 months.

Because high-dose chemotherapy is capable of bypassing the blood-brain barrier (BBB) to increase the drug concentration in brain tumours, we adopted high-dose pemetrexed $\left(900 \mathrm{mg} / \mathrm{m}^{2}\right)$, based on the safety and toxicity analyses of phase I studies, to investigate the efficacy and safety of pemetrexed in patients with NSCLC BM (15-17).

Pharmacological therapy for metastatic disease in the central nervous system (CNS) is complicated by the BBB. Temozolomide is a second-generation alkylating agent, with nearly $100 \%$ bioavailability, and is administered orally. Temozolomide readily crosses the BBB, achieving cerebrospinal fluid concentrations that are approximately $30 \%$ of plasma concentrations in both animal and human models (18). Preclinical and phase I trials have shown the additive and synergistic activity of temozolomide combined with other chemotherapeutic agents against solid tumours (19). Toxicity is lower, with fewer than $5 \%$ of patients experiencing myelosuppression (20).

In this prospective cohort study, we compared the efficacy and safety of pemetrexed plus cisplatin (PC) versus pemetrexed plus temozolomide (PT) in patients with BM from NSCLC.

\section{Patients and Methods}

Patients. Between November 2013 and October 2015, 60 patients with histologically or cytologically confirmed lung adenocarcinomas with BM were treated with PC (32 patients) or PT (28 patients). Eligible patients were from three institutions, with a Karnofsky Performance status (KPS) of $\geq 70$ and a life expectancy of 8 weeks or longer. In these patients, surgery or radiosurgery of BM was not deemed appropriate.

Baseline evaluations included a complete medical history, physical and neurologic examinations, a determination of the Eastern Co-operative Oncology Group performance status (ECOG PS), a haematological evaluation, and clinical chemistry assessments (including liver and renal function tests). The baseline tumour size was determined by gadolinium-enhanced magnetic resonance imaging (MRI) of the brain. Haematological tests were repeated on day 22 of each cycle. Brain MRI or computed tomographic scans were required every 2 to 3 cycles and 4 weeks after the last course of treatment.

Exclusion criteria included uncontrolled pleural or pericardial effusion or ascites, a severe and uncontrolled complication, uncontrollable diabetes mellitus or hypertension (blood pressure $\geq 150 / 100 \mathrm{mmHg}$ ), clinically significant cardiovascular disease, pregnancy or lactation, a history of active double cancer, and an unstable psychiatric disorder.

The trial is registered under the number NCT02284490 and was approved by the Ethics Committee of Shandong Cancer Hospital, Qingdao University affiliated Yantai Yuhuangding Hospital, and Shandong University affiliated Qilu Hospital. All enrolled patients, by signing the consent form, stated that they were capable of understanding the diagnosis and nature of treatment.

Treatment. All patients underwent WBRT prescribed at a dose of 30 Gy/10 fractions for 5 days per week up to 2 weeks. At least 2 weeks after the completion of WBRT, pemetrexed $\left(900 \mathrm{mg} / \mathrm{m}^{2}\right)$ plus cisplatin $\left(20 \mathrm{mg} / \mathrm{m}^{2}\right)$ were administered on day 1 and days $1-3$, respectively, in the PC group. In the PT group, temozolomide $\left(75 \mathrm{mg} / \mathrm{m}^{2}\right)$ was administered concomitant with WBRT and followed by pemetrexed $\left(900 \mathrm{mg} / \mathrm{m}^{2}\right)$ plus temozolomide $\left(150 \mathrm{mg} / \mathrm{m}^{2}\right)$ on day 1 and days $1-5$, respectively. The chemotherapy was repeated every 21 days for six cycles. All patients received oral folic acid $(400 \mu \mathrm{g})$ daily and a vitamin B12 injection $(1,000 \mu \mathrm{g})$ every 9 weeks, beginning at least 1 week before the first dose and continuing until 3 weeks after the last dose of the study treatment. If the disease became stable after therapy, the patients continued receiving high-dose pemetrexed $\left(900 \mathrm{mg} / \mathrm{m}^{2}\right)$ as maintenance therapy until eventual disease progression or the development of intolerable toxicities. Concomitant supportive therapies, such as erythropoietic agents or granulocyte colonystimulating factors, were allowed according to the American Society of Clinical Oncology guidelines (21).

Response evaluation and statistical analysis. The patients were followed up using brain gadolinium-enhanced MRI after 2-3 cycles of treatment. The tumour responses were evaluated according to the Response Assessment in Neuro-oncology (RANO (22)) by MRI. Patients who were unable to undergo MRI due to internal metal objects or other reasons were ineligible. Treatment related toxicity was evaluated according to the National Cancer Institution Common Terminology Criteria for Adverse Events 3.0 (23). The Patients who had not experienced progression or not died during the study were censored on the date of the last tumour assessment.

The primary endpoints were ORR, PFS, and OS, secondary endpoints included safety and tolerability. ORR was based on the best response measured according to the RANO. PFS was defined as the time from treatment initiation to the first occurrence of disease progression or death. OS was defined as the time from treatment initiation to the date of death from any cause. Patients who had not experienced progression or death during the study were terminated on the date of the last tumor assessment.

Treatment related toxicity was evaluated according to the National Cancer Institution Common Terminology Criteria for Adverse Events 3.0.

Statistical analysis was carried out using Statistical Product and Service Solutions version 17 (SPSS Inc., Chicago, IL, USA). The tumour response rate was calculated as the proportion of qualified 
patients with a best tumour response between the arms using the Mann-Whitney $U$-test. OS, PFS and the differences between groups in survival were estimated using the Kaplan-Meier method.

\section{Results}

Patients. Between November 2013 and October 2015, 60 patients were enrolled into this phase II trial at three centres. Thirty-two patients were included in the PC group, and 28 patients entered the PT group. All patients had adenocarcinoma and were eligible for the statistical analysis. Their demographic and clinical characteristics are shown in Table I.

Treatment. All patients received standard WBRT (30 Gy, 10 fractions) and the $\mathrm{PT}$ group received concomitant temozolomide. A median of six cycles (range=2-6 cycles) of chemotherapy followed for both groups. All enrolled patients received follow-up evaluations. The follow-up rate was $100 \%$. Seven out of the $32(21.9 \%)$ patients in the PC group and four out of the $28(14.3 \%)$ patients in the PT group received maintenance chemotherapy, consisting of high-dose $\left(900 \mathrm{mg} / \mathrm{m}^{2}\right)$ pemetrexed and cisplatin or other second-line therapies.

Efficacy. All 60 patients were eligible for response assessments. The 53 patients with CNS symptoms had symptom relief in both groups. Regarding the primary endpoint, the PC group had an ORR [complete response (CR) plus progressive disease (PR)] of $68.8 \%(\mathrm{CR}: 18.8 \%, \mathrm{PR}$ : $50 \%$ ), and the PT group had an ORR of $75 \%$ (CR: $21.4 \%$, PR: $53.6 \%$ ) (Table II). There was no statistically significant difference in response between the two groups $(p=0.711)$.

The median PFS and OS were 13.6 months (range, 2-22.5 months) and 18.9 months (range=2.8-22.5 months), respectively, in the PC group, and 16.9 months (range, 5.024.4 months) and 19.3 months (range, 8.5-25.3 months), respectively, in the PT group. There were no statistically significant differences in the PFS and OS between the groups (Figure 1).

By the end of the analysis, 25 patients and 22 patients had died of disease progression in the PC group and PT group, respectively; seven and six patients in the PC group and PT group, respectively, have continued follow-up. According to the PARAMOUNT result, four patients out of seven $(57.1 \%)$ in the PC group received high-dose pemetrexed $\left(900 \mathrm{mg} / \mathrm{m}^{2}\right)$ as a maintenance therapy, and the other three patients $(42.9 \%)$ received second-line or higher therapy due to disease progression. In the PC group, one patient out of six $(16.7 \%)$ received high-dose pemetrexed $\left(900 \mathrm{mg} / \mathrm{m}^{2}\right)$ as a maintenance therapy, and the other five patients $(83.3 \%)$ received second-line or higher therapy due to disease progression. Decisions regarding which therapies to use were made by the individual investigators.
Table I. Patient characteristics.

\begin{tabular}{lcc}
\hline Characteristic & $\begin{array}{c}\text { PC group, } \\
\text { N }=32\end{array}$ & $\begin{array}{c}\text { PT group } \\
\text { N }=28\end{array}$ \\
& & \\
\hline Median age (range), years & $59(52-73)$ & $58.5(45-77)$ \\
Gender, n (\%) & $11(34.4)$ & $11(39.3)$ \\
Male & $21(65.6)$ & $17(60.7)$ \\
Female & $85(70-100)$ & $85(70-100)$ \\
Median KPS (range) & & \\
Smoker, n (\%) & $10(31.3)$ & $9(32.1)$ \\
Yes & $22(68.7)$ & $19(67.9)$ \\
No & & \\
Number of brain metastases, n (\%) & $11(34.4)$ & $10(35.7)$ \\
1 & $6(18.8)$ & $7(25)$ \\
2,3 & $15(46.8)$ & $11(39.3)$ \\
$>3$ & $14(4-48)$ & $12.5(2-37)$ \\
Median tumor diameter (range), mm & & \\
CNS symptoms & $4(12.5)$ & $3(10.7)$ \\
No & $14(43.8)$ & $10(35.7)$ \\
Headache & $3(9.4)$ & $2(7.1)$ \\
Pyramidal sign & $4(12.5)$ & $4(14.3)$ \\
Epileptic seizure & $7(21.8)$ & $5(17.9)$ \\
Other & & \\
Extracranial metastases & $17(53.1)$ & $14(50)$ \\
Yes & $15(46.9)$ & $4(50)$ \\
No & $6(2-6)$ & $6(2-6)$ \\
Number of completed cycles & $14(43.7)$ & $13(46.4)$ \\
Median (range) & $18(56.3)$ & $15(53.6)$ \\
$<6$ Cycles & & \\
$\geq 6$ Cycles & & \\
\hline
\end{tabular}

PC, Pemetrexed with cisplatin; PT, pemetrexed with temezolomide; KPS, Karnofsky performance status; CNS, central nervous system.

Table II. Best cerebral response rates

\begin{tabular}{lcc}
\hline Tumor response & $\begin{array}{c}\mathrm{PC}, \mathrm{n}(\%) \\
(\mathrm{n}=32)\end{array}$ & $\begin{array}{c}\mathrm{PT}, \mathrm{n}(\%) \\
(\mathrm{n}=28)\end{array}$ \\
\hline $\mathrm{CR}$ & $6(18.8)$ & $6(21.4)$ \\
$\mathrm{PR}$ & $16(50)$ & $15(53.6)$ \\
$\mathrm{SD}$ & $8(25)$ & $4(14.3)$ \\
PD & $2(6.3)$ & $3(10.7)$ \\
ORR & $22(68.8)$ & $12(75)$ \\
\hline
\end{tabular}

CR, Complete response; PR, partial response; SD, stable disease; PD, progression disease; $\mathrm{ORR}$, objective response rate $(\mathrm{CR}+\mathrm{PR})$.

Safety. Toxicities are summarized in Table III. Regarding leucopenia, neutropoenia, anaemia, thrombocytopoenia, nausea/vomiting, alopecia, rash, fatigue, renal insufficiency, hepatic insufficiency, oral mycosis, constipation and diarrhoea, no side effects of grade 4 or higher were observed in either group. In the PC group, grade 3 toxicities included leucopenia, nausea/vomiting, alopecia and skin rash. In the 

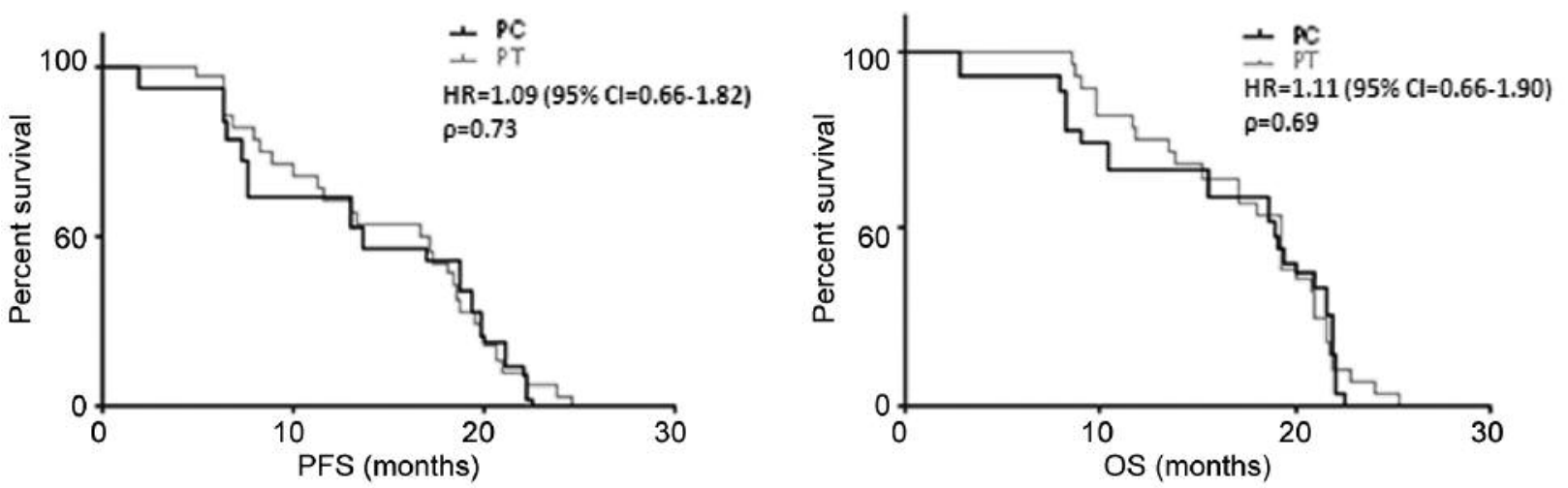

Figure 1. The progression-free survival (PFS) and overall survival (OS) of the group of patients treated with pemetrexed plus cisplatin (PC) versus that treated with pemetrexed plus temozolomide (PT). The median PFS and OS were 13.6 months (range=2-22.5 months) and 18.9 months (range =2.8-22.5 months), respectively, in the PC group and 16.9 months (range=5.0-24.4 months) and 19.3 months (range=8.5-25.3 months), respectively, in the PT group. There were no statistically significant differences in the PFS and OS between the groups. HR: Hazard ratio; CI, confidence interval.

Table III. Toxicities.

\begin{tabular}{|c|c|c|c|c|}
\hline \multirow[t]{2}{*}{ Toxicity } & \multicolumn{4}{|c|}{ Cases $(\%), \mathrm{PC} / \mathrm{PT}$} \\
\hline & Grade 1 & Grade 2 & Grade 3 & Total \\
\hline \multicolumn{5}{|l|}{ Hematological } \\
\hline Leucopenia & $5(15.6) / 3(10.7)$ & $4(12.5) / 1(3.6)$ & $2(6.3) / 2(7.1)$ & $11(34.4) / 6(21.4)$ \\
\hline Neutropenia & $5(15.6) / 2(7.1)$ & $3(9.4) / 1(3.6)$ & $0 / 0$ & $8(25) / 3(10.7)$ \\
\hline Anaemia & $2(6.3) / 1(3.6)$ & $3(9.4) / 2(7.1)$ & $0 / 0$ & $5(15.6) / 3(10.7)$ \\
\hline Thrombocytopenia & $3(9.4) / 1(3.6)$ & $1(3.1) / 0$ & $0 / 0$ & $4(12.5) / 1(3.6)$ \\
\hline \multicolumn{5}{|l|}{ Nonhaematological } \\
\hline Nausea/vomiting & $17(53.1) / 12(42.9)$ & $5(15.6) / 2(7.1)$ & $2(6.3) / 2(7.1)$ & $24(75) / 16(57.1)$ \\
\hline Alopecia & $8(25) / 6(21.4)$ & $21(65.6) / 10(35.7)$ & $1(3.1) / 0$ & $30(94) / 16(57.1)$ \\
\hline Skin (rash) & $3(9.4) / 3(10.7)$ & $7(21.9) / 1(3.6)$ & $3(9.4) / 0$ & $13(40.6) / 4(14.3)$ \\
\hline Fatigue & $2(6.3) / 1(3.6)$ & $2(6.3) / 0$ & $0 / 0$ & $4(12.5) / 1(3.6)$ \\
\hline Renal insufficiency & $1(3.1) / 0$ & $0 / 0$ & $1(3.1) / 0$ & $2(6.3) / 0$ \\
\hline Hepatic insufficiency & $0 / 0$ & $2(6.3) / 1(3.6)$ & $0 / 0$ & $2(6.3) / 1(3.6)$ \\
\hline Oral mycosis & $3(9.4) / 0$ & $0 / 0$ & $0 / 0$ & $3(9.4) / 0$ \\
\hline Constipation & $5(15.6) / 1(3.6)$ & $1(3.1) / 0$ & $0 / 0$ & $6(18.8) / 1(3.6)$ \\
\hline Diarrhoea & $2(6.3) / 1(3.6)$ & $0 / 0$ & $0 / 0$ & $2(6.3) / 1(3.6)$ \\
\hline
\end{tabular}

PC, Pemetrexed with cisplatin; PT, pemetrexed with temezolomide.

PT group, Grade 3 toxicities only included leucopenia and nausea/vomiting. Grade 1 and 2 toxicities in the PT group were fewer than in the PC group. The results suggested that the toxicities in the PT group were fewer and milder than in the PC group. All side effects were well tolerated. Toxicity during the maintenance phase was minimal.

\section{Discussion}

This three-institution phase II study revealed that high-dose pemetrexed plus cisplatin or temozolomide was effective for NSCLC with BM, when surgery or radiosurgery was not possible. The efficacies of the two regimens did not differ.
Compared to the $\mathrm{PC}$ regimen, the $\mathrm{PT}$ regimen had significantly less toxicity in patients with adenocarcinoma and BM. Our data suggest that both regimens led to better intracranial response rates, the ORRs were $68.8 \%$ in the PC group and $75 \%$ in the PT group, with a remarkably CR for BM of $18.8 \%(6 / 32)$ and $21.4 \%(6 / 28)$, respectively.

The median PFS and OS were 13.6 months (range=2-22.5 months) and 18.9 months (range=2.8-22.5 months), respectively, in the PC group and 16.9 months (range, 5.0-24.4 months) and 19.3 months (range=8.5-25.3 months), respectively, in the PT group. There were no statistically significant differences in the PFS and OS between the groups. The results were comparable to other chemotherapeutic agents 
used in NSCLC with BM $(8,14,24-27)$. There are three possible reasons for our longer PFS and OS: (a) all patients had cytologically- or histologically-proven lung adenocarcinoma, with a statistically significantly higher mean survival time than for patients with other histologies of NSCLC with BM (28); (b) patients enrolled in this study were all eligible for WBRT with KPS $\geq 70$, which may sensitize tumours to our regimen; and (c) the synergistic efficacy of high-dose pemetrexed plus cisplatin or temozolomide after WBRT may have led to these encouraging results.

The role of chemotherapy for the treatment of BM arising from lung cancer has been limited by poor efficacy and high toxicity. Many investigators have been discouraged by the concern that chemotherapy drugs that would have efficacy against the primary tumour (e.g., lung carcinoma), such as vincristine, doxorubicin, and carboplatin, would not cross the $\mathrm{BBB}$ and would therefore not be active against metastatic disease (29). However, the data suggest that the BBB is disrupted when $\mathrm{BM}$ are present, with reports showing that the concentration of chemotherapy drugs, including platinum, is similar in intracerebral and extracerebral tumours $(30,31)$.

Administration of chemotherapy at full dose with maximal activity against local and micrometastatic disease is highly desirable. Pemetrexed, a multitarget antifolate chemotherapy agent, inhibits the thymidylate synthase enzyme, resulting in a decrease in the thymidine that is necessary for pyrimidine synthesis. Pemetrexed also inhibits dihydrofolate reductase and glycinamide ribonucleotide formyl transferase, the latter of which is a folate-dependent enzyme involved in purine synthesis. Supplemented with intermittent folic acid or with continuous daily multivitamins containing nutritional doses of folic acid, pemetrexed was administered up to $1,050 \mathrm{mg} / \mathrm{m}^{2}$ in a cancer-treatment trial (15-17).

Temozolomide has a demonstrated preclinical activity against a variety of solid tumours (32). Temozolomide is orally bioavailable and well tolerated, enabling it to be used in heavily pretreated patients and in combination with other agents. It readily crosses the $\mathrm{BBB}$, achieving excellent concentrations in the brain, which makes it an attractive agent against BM $(33,34)$. Preclinical data indicate that combination of temozolomide with other chemotherapeutic agents may produce additive or synergistic responses (19). Temozolomide is therefore an excellent candidate for use in combination chemotherapy for the treatment of BM arising from lung cancer (35).

Pemetrexed plus cisplatin has been demonstrated to be efficacious in the first-line management of stage IV NSCLC $(1,36)$. Because temozolomide has several properties in the treatment of BM, we designed this study to compare the efficacy and safety between high-dose pemetrexed plus cisplatin and high-dose pemetrexed plus temozolomide.

In conclusion, treatment with pemetrexed plus temozolomide demonstrated a clinically equivalent efficacy with a significantly improved safety profile compared to pemetrexed plus cisplatin for NSCLC with BM in this study. Further randomized trials should be conducted to confirm our results.

\section{Conflicts of Interest}

The Authors declare that there are no conflicts of interest in regard to this study.

\section{References}

1 Klos KJ and O'Neill BP: Brain metastases. Neurologist 10: 3146, 2004.

2 Posner JB: Neurologic complications of systemic cancer. Dis Mon: DM 25: 1-60, 1978.

3 Sanchez de Cos J, Sojo Gonzalez MA, Montero MV, Perez Calvo MC, Vicente MJ and Valle MH: Non-small cell lung cancer and silent brain metastasis. Survival and prognostic factors. Lung Cancer 63: 140-145, 2009.

4 Millar BA and Laperriere NJ: In regard to Sanghavi, Miranpuri and Chappell et al: radiosurgery for patients with brain metastases: a multi-institutional analysis stratified by the RTOG recursive partitioning analysis method. IJROBP 2001; 51: 426-434. Int J Radiat Oncol Biol Phys 53: 252; author reply 252-253, 2002.

5 Chitapanarux I, Goss B, Vongtama R, Frighetto L, De Salles A, Selch M, Duick M, Solberg T, Wallace R, Cabatan-Awang C and Ford J: Prospective study of stereotactic radiosurgery without whole brain radiotherapy in patients with four or less brain metastases: incidence of intracranial progression and salvage radiotherapy. J Neurooncol 61: 143-149, 2003.

6 Andrews DW, Scott CB, Sperduto PW, Flanders AE, Gaspar LE, Schell MC, Werner-Wasik M, Demas W, Ryu J, Bahary JP, Souhami L, Rotman M, Mehta MP and Curran WJ Jr.: Whole brain radiation therapy with or without stereotactic radiosurgery boost for patients with one to three brain metastases: phase III results of the RTOG 9508 randomised trial. Lancet 363: 1665-1672, 2004.

7 Kocher M, Maarouf M, Bendel M, Voges J, Muller RP and Sturm $\mathrm{V}$ : Linac radiosurgery versus whole brain radiotherapy for brain metastases. A survival comparison based on the RTOG recursive partitioning analysis. Strahlenther Onkol 180: 263-267, 2004.

8 Yawn BP, Wollan PC, Schroeder C, Gazzuola L and Mehta M: Temporal and gender-related trends in brain metastases from lung and breast cancer. Minn Med 86: 32-37, 2003.

9 Kepka L, Cieslak E, Bujko K, Fijuth J and Wierzchowski M: Results of the whole-brain radiotherapy for patients with brain metastases from lung cancer: the RTOG RPA intra-classes analysis. Acta Oncol 44: 389-398, 2005.

10 Rades D, Schild SE, Lohynska R, Veninga T, Stalpers LJ and Dunst J: Two radiation regimens and prognostic factors for brain metastases in nonsmall cell lung cancer patients. Cancer 110: 1077-1082, 2007.

11 Robinet G, Thomas P, Breton JL, Lena H, Gouva S, Dabouis G, Bennouna J, Souquet PJ, Balmes P, Thiberville L, Fournel P, Quoix E, Riou R, Rebattu P, Perol M, Paillotin D and Mornex F: Results of a phase III study of early versus delayed whole brain radiotherapy with concurrent cisplatin and vinorelbine combination in inoperable brain metastasis of non-small-cell lung cancer: Groupe Francais de Pneumo-Cancerologie (GFPC) Protocol 95-1. Ann Oncol 12: 59-67, 2001. 
12 Moscetti L, Nelli F, Felici A, Rinaldi M, De Santis S, D'Auria G, Mansueto G, Tonini G, Sperduti I and Pollera FC: Up-front chemotherapy and radiation treatment in newly diagnosed nonsmall cell lung cancer with brain metastases: survey by Outcome Research Network for Evaluation of Treatment Results in Oncology. Cancer 109: 274-281, 2007.

13 Dinglin XX, Huang Y, Liu H, Zeng YD, Hou X and Chen LK: Pemetrexed and cisplatin combination with concurrent whole brain radiotherapy in patients with brain metastases of lung adenocarcinoma: a single-arm phase II clinical trial. J Neurooncol 112: 461-466, 2013.

14 Barlesi F, Gervais R, Lena H, Hureaux J, Berard H, Paillotin D, Bota S, Monnet I, Chajara A and Robinet G: Pemetrexed and cisplatin as first-line chemotherapy for advanced non-small-cell lung cancer (NSCLC) with asymptomatic inoperable brain metastases: a multicenter phase II trial (GFPC 07-01). Ann Oncol 22: 2466-2470, 2011.

15 Dittrich C, Petruzelka L, Vodvarka P, Gneist M, Janku F, Kysela T, Melemed A, Latz J, Simms L and Krejcy K: A phase I study of pemetrexed (ALIMTA) and cyclophosphamide in patients with locally advanced or metastatic breast cancer. Clin Cancer Res 12: 7071-7078, 2006.

16 Nakagawa K, Kudoh S, Matsui K, Negoro S, Yamamoto N, Latz JE, Adachi S and Fukuoka M: A phase I study of pemetrexed (LY231514) supplemented with folate and vitamin B12 in Japanese patients with solid tumours. Br J Cancer 95: 677-682, 2006.

17 Takimoto CH, Hammond-Thelin LA, Latz JE, Forero L, Beeram M, Forouzesh B, de Bono J, Tolcher AW, Patnaik A, Monroe P, Wood L, Schneck KB, Clark R and Rowinsky EK: Phase I and pharmacokinetic study of pemetrexed with high-dose folic acid supplementation or multivitamin supplementation in patients with locally advanced or metastatic cancer. Clin Cancer Res 13: 2675-2683, 2007.

18 Patel M, McCully C, Godwin K and Balis FM: Plasma and cerebrospinal fluid pharmacokinetics of intravenous temozolomide in non-human primates. J Neurooncol 61: 203-207, 2003.

19 Prados M: Temozolomide in combination with other cytotoxic agents. Semin Oncol 28: 24-33, 2001.

20 Abrey LE and Christodoulou C: Temozolomide for treating brain metastases. Semin Oncol 28: 34-42, 2001.

21 Pfister DG, Johnson DH, Azzoli CG, Sause W, Smith TJ, Baker S, Jr., Olak J, Stover D, Strawn JR, Turrisi AT, Somerfield MR and American Society of Clinical O: American Society of Clinical Oncology treatment of unresectable non-small-cell lung cancer guideline: update 2003. J Clin Oncol 22: 330-353, 2004.

22 Wen PY, Macdonald DR, Reardon DA, Cloughesy TF, Sorensen AG, Galanis E, Degroot J, Wick W, Gilbert MR, Lassman AB, Tsien C, Mikkelsen T, Wong ET, Chamberlain MC, Stupp R, Lamborn KR, Vogelbaum MA, van den Bent MJ and Chang SM: Updated response assessment criteria for high-grade gliomas: response assessment in neuro-oncology working group. J Clin Oncol 28: 1963-1972, 2010.

23 Trotti A, Colevas AD, Setser A, Rusch V, Jaques D, Budach V, Langer C, Murphy B, Cumberlin R, Coleman CN and Rubin P: CTCAE v3.0: development of a comprehensive grading system for the adverse effects of cancer treatment. Semin Radiat Oncol 13: 176-181, 2003.

24 Vecht CJ, Haaxma-Reiche H, Noordijk EM, Padberg GW, Voormolen JH, Hoekstra FH, Tans JT, Lambooij N, Metsaars JA,
Wattendorff AR et al: Treatment of single brain metastasis: radiotherapy alone or combined with neurosurgery? Ann Neurol 33: 583-590, 1993.

25 Schoggl A, Kitz K, Reddy M, Wolfsberger S, Schneider B, Dieckmann $K$ and Ungersbock K: Defining the role of stereotactic radiosurgery versus microsurgery in the treatment of single brain metastases. Acta Neurochir (Wien) 142: 621-626, 2000.

26 DeAngelis LM: Management of brain metastases. Cancer Invest 12: 156-165, 1994.

27 Coia LR: The role of radiation therapy in the treatment of brain metastases. Int J Radiat Oncol Biol Phys 23: 229-238, 1992.

28 Guo S, Reddy CA, Chao ST, Suh JH, Barnett GH, Vogelbaum MA and Videtic GM: Impact of non-small cell lung cancer histology on survival predicted from the graded prognostic assessment for patients with brain metastases. Lung Cancer 77: 389-393, 2012.

29 Minotti V, Crino L, Meacci ML, Corgna E, Darwish S, Palladino MA, Betti M and Tonato M: Chemotherapy with cisplatin and teniposide for cerebral metastases in non-small cell lung cancer. Lung Cancer 20: 93-98, 1998.

30 Stewart DJ, Leavens M, Friedman J, Benjamin RS, Moore EC, Bodey GP, Valdivieso M, Burgess MA, Wiseman C and Loo TL: Penetration of $\mathrm{N}$-(phosphonacetyl)-L-aspartate into human central nervous system and intracerebral tumor. Cancer Res 40: 3163-3166, 1980.

31 Stewart DJ, Leavens M, Maor M, Feun L, Luna M, Bonura J, Caprioli R, Loo TL and Benjamin RS: Human central nervous system distribution of cis-diamminedichloroplatinum and use as a radiosensitizer in malignant brain tumors. Cancer Res 42: 2474-2479, 1982.

32 Raymond E, Izbicka E, Soda H, Gerson SL, Dugan M and Von Hoff DD: Activity of temozolomide against human tumor colony-forming units. Clin Cancer Res 3: 1769-1774, 1997.

33 Baker SD, Wirth M, Statkevich P, Reidenberg P, Alton K, Sartorius SE, Dugan M, Cutler D, Batra V, Grochow LB, Donehower RC and Rowinsky EK: Absorption, metabolism, and excretion of 14C-temozolomide following oral administration to patients with advanced cancer. Clin Cancer Res 5: 309-317, 1999.

34 Ostermann S, Csajka C, Buclin T, Leyvraz S, Lejeune F, Decosterd LA and Stupp R: Plasma and cerebrospinal fluid population pharmacokinetics of temozolomide in malignant glioma patients. Clin Cancer Res 10: 3728-3736, 2004.

35 Ebert BL, Niemierko E, Shaffer K and Salgia R: Use of temozolomide with other cytotoxic chemotherapy in the treatment of patients with recurrent brain metastases from lung cancer. Oncologist 8: 69-75, 2003.

36 Bailon O, Chouahnia K, Augier A, Bouillet T, Billot S, Coman I, Ursu R, Belin C, Zelek L, Des Guetz G, Levy C, Carpentier AF and Morere JF: Upfront association of carboplatin plus pemetrexed in patients with brain metastases of lung adenocarcinoma. Neuro Oncol 14: 491-495, 2012. 